\title{
Differential Transmission of Isolates of the High Plains virus by Different Sources of Wheat Curl Mites
}

\author{
Dallas L. Seifers, Professor, Kansas State University, Agricultural Research Center-Hays, Hays 67601-9228; Tom \\ L. Harvey, Professor, Department of Entomology, Kansas State University, Manhattan 66506; Raymond Louie, \\ USDA-ARS, and D. T. Gordon, Professor, Department of Plant Pathology, The Ohio State University, Wooster \\ 44691; and T. J. Martin, Professor, Kansas State University, Agricultural Research Center-Hays
}

\begin{abstract}
Seifers, D. L., Harvey, T. L., Louie, R., Gordon, D. T., and Martin, T. J. 2002. Differential transmission of isolates of the High Plains virus by different sources of wheat curl mites. Plant Dis. $86: 138-142$

High Plains virus (HPV) isolates from Colorado, Idaho, Kansas, Texas, and Utah were serologically related, had similar relative molecular masses (sodium dodecyl sulfate-polyacrylamide gel electrophoresis) for the 32-kDa diagnostic HPV protein, and were transmissible and maintained free of Wheat streak mosaic virus (WSMV) by vascular puncture inoculation. Collections of wheat curl mites (Aceria tosichella Keifer; WCM) from Kansas, Montana, Nebraska, South Dakota, and Texas differentially transmitted these isolates. For collections from South Dakota and Texas, little or no HPV transmission occurred, whereas WCM from Nebraska and Montana transmitted all five isolates. The collection from Kansas mostly transmitted only one HPV isolate. Aviruliferous or viruliferous WSMV Nebraska WCM transmitted HPV at similar rates and aviruliferous Montana WCM transmitted HPV at lower levels than viruliferous Montana WCM.
\end{abstract}

Additional keywords: vascular puncture inoculation, vector

In 1993, a previously unknown pathogen was identified in corn (Zea mays L.) from Colorado, Idaho, Kansas, and Texas (5). The pathogen was associated with a 32$\mathrm{kDa}$ protein and antiserum prepared to this protein preferentially reacted to it in enzyme-linked immunosorbent assay (ELISA) and Western blot assay $(6,18)$. Threadlike virus particles from symptomatic corn leaves infected by this pathogen were observed in electron microscope studies (1). These particles were preferentially labeled when probed in immunogoldlabeling experiments using antiserum to the $32-\mathrm{kDa}$ protein. In this same study, double-membrane bodies were observed in thin sections of virus-infected cells. When probed with the same antiserum, the center, but not the membranes, of these bodies were decorated with the gold-labeled antibodies.

In other studies, several double-stranded RNA segments were identified from virusinfected tissue (5). The nucleotide se-

Corresponding author: D. L. Seifers

E-mail: dseifers@oznet.ksu.ed

Contribution No. 01-369-J from the Kansas Agricultural Experiment Station. Research was supported in part by a grant from Pioneer Hybrid International, Inc., Johnston, IA 50131.

Accepted for publication 10 October 2001

Publication no. D-2001-1204-01R

(C) 2002 The American Phytopathological Society quence of RNA3 of the segments was determined and deposited in the GenBank (Accession No. U60141; J. S. Hall, S. G. Jensen, and R. C. French, 1996, unpublished data). The nucleotide sequence was stated to be the probable N-protein of the virus. These data support the viral identity of the pathogen, which was named the High Plains virus (HPV; 6).

HPV is transmitted by wheat curl mites (Aceria tosichella Keifer) (WCM; 18). Plants naturally infested in the field by WCM vectoring HPV include wheat (Triticum aestivum L.), barley (Hordeum vulgare L.), corn, yellow foxtail (Setaria glauca (L.) Beauv.), and green foxtail ( $S$. viridis (L.) Beauv.) (19). The incidence of High Plains disease declines as distance from infected volunteer wheat increases, as expected for the WCM vector (18). WCM are also a vector of Wheat streak mosaic virus (WSMV; 21), which infects corn and wheat in the United States (21). WSMV causes major crop losses in wheat and WCM play a major role in the occurrence of wheat streak in the United States. In recent years, WCM have been reported to simultaneously transmit WSMV and HPV in the field (18).

WCM also play an integral role in the epidemiology of the High Plains disease; therefore, we wanted to determine the ability of different collections of WCM to transmit various HPV isolates. Our goals were to (i) acquire and maintain different cultures of WCM from different states, (ii) obtain HPV isolates from several states and maintain them free of WSMV, (iii) determine the relationships among the isolates based on serological reactivites and the relative molecular masses of the diagnostic HPV protein, and (iv) determine the ability of the different WCM sources to transmit the different HPV isolates in the presence or absence of WSMV.

\section{MATERIALS AND METHODS}

Sources and maintenance of WCM and infestation of plants. All WCM were obtained from wheat. The WCM collections were obtained from Kansas (KS WCM; Tom Harvey, Ellis County), Nebraska (NE WCM; Gary Hein, University of Nebraska, Scottsbluff), South Dakota (SD WCM; R. D. Collins, South Dakota State University), Montana (MT WCM; Sue Blodgett, Montana State University), and Texas (TX WCM; C. Rush, Texas A\&M University, Bushland). The WCM collection from each state was raised from eggs and increased on caged 'Tomahawk' wheat (18). After aviruliferous WCM colonies were established, a portion of the WCM from each state was used to infest Tomahawk wheat plants previously inoculated with the WSMV isolate obtained by mechanical inoculation from the wheat from which the WCM originally were obtained. This acquisition resulted in WCM colonies from each state that were either aviruliferous or viruliferous for the WSMV isolate from the state of the WCM. Plants used as a source for WCM for HPV acquisition were assayed by ELISA for HPV and WSMV prior to use. Identifications of the WCM used in this study were confirmed by J. W. Amrine (West Virginia University, Morgantown, WV) as Aceria tosichella Keifer.

All corn plants used for HPV acquisition were pretested at 21 days following vascular puncture inoculation (VPI) by ELISA with HPV and WSMV antiserum. Plants were selected that approached an ELISA absorbance value for HPV of 0.300 (range of 0.275 to 0.325 ) as explained below. This value was relatively high, indicating a high virus titer. It was believed that a uniformly high virus titer might reduce the influence of differences in HPV titer on virus acquisition. Leaves used were usually from the same plant, but occasionally from different plants. Leaves with an appropriate ELISA value were mixed and randomly 
selected for HPV acquisition by a given WCM source. To acquire HPV, leaf pieces bearing aviruliferous or viruliferous WCM reared on wheat were clipped to a piece of HPV-infected 'Spirit' corn leaf tissue that had tested positive for HPV and negative for WSMV by ELISA. The WCM were allowed a 24-h acquisition access period. Ten WCM (adults or nymphs showing movement) were then transferred, using a hair glued to a wooden dowel, from HPVinfected source tissue to each of 25 'Westford' barley assay plants (18). In addition, if sufficient WCM remained after the 10 WCM transfers, the remaining WCM were used to infest additional assay plants with approximately $100 \mathrm{WCM}$ per plant. The number of plants infested with $100 \mathrm{WCM}$ was a function of the number of remaining WCM. Following infestation of the barley assay plants, the WCM were allowed a 24$\mathrm{h}$ inoculation access period and then all test plants were treated with carbofuran (27 $\mathrm{mg} / \mathrm{liter}$ ) to kill the WCM. The WCM and HPV source plants and test plants were covered with plastic cages before and after infestation (18). Controls consisted of WCM fed on healthy corn and then transferred to five barley assay plants as described above for HPV acquisition. HPV transmission to barley test plants was assayed by symptom expression and ELISA using HPV and WSMV antiserum. HPV source plants, wheat used for WCM rearing, and barley assay plants were all held in different greenhouses under natural daylight with a temperature range 20 to $31^{\circ} \mathrm{C}$. The experiment was repeated three times.

Percentage data (number of HPV-infected barley assay plants for the $10 \mathrm{WCM}$ treatments for the three experiments) were arcsine transformed before analysis of variance when the range of percentages among treatments was greater than 40 (9), and differences among means were compared using a simple least significant difference test. For the 100-WCM data, logistic regression analysis was used because of small plant numbers and incomplete data sets and the data were analyzed with Statistical Analysis System software (SAS Institute, Cary, NC).

Sources and maintenance of HPV isolates. The HPV isolates were obtained from corn from Colorado (CO HPV; Bob Hammond, 1996, Fruita, CO), Idaho (ID HPV; Bob Forster, 1997), Kansas (KS HPV; Ellis Co., 1996), Texas (TX HPV; C. Rush, Texas A\&M, University, Bushland, 1996), and Utah (UT HPV; S. Jensen from sample received from Utah, 1996). The HPV isolates were maintained in corn by VPI of 'Spirit' corn seed as previously described (10). Briefly, inoculum was prepared by grinding $(1: 5 \mathrm{wt} / \mathrm{vol})$ corn leaves with a wooden applicator stick (Fisher 01340 , Norcross, GA) in a $1.5-\mathrm{ml}$ microfuge tube containing MBS-EDTA buffer $(0.2 \mathrm{M}$ mannitol, 0.07 M sucrose, 0.5 M Tris- $\mathrm{HCl}$,
0.01 M EDTA, 0.022 M NaDIECA, 0.022 $\mathrm{M}$ sodium sulphite, and $0.005 \mathrm{M}$ dithiothreitol, $\mathrm{pH}$ 7.4). Spirit corn seeds were given a preinoculation soak (100 seed in $50 \mathrm{ml}$ of distilled water) for $4 \mathrm{~h}$ at $30^{\circ} \mathrm{C}$. Seed (100) were placed in a glass dish, 21 by 21 by $5 \mathrm{~cm}$, lined with eight sheets of paper towels moistened with $50 \mathrm{ml}$ of distilled water. Inoculum $(5 \mu \mathrm{l})$ was placed on the embryo side of each kernel. In earlier inoculations, each seed was inoculated using a single minuten pin mounted in an inoculating loop holder (Thomas Scientific, 7011-D70, Swedesboro, NJ), with the loop holder mounted on an electric engraver (Burgess Model 75, New York Mills, NY, from Fisher \#13-38910). In later inoculations, the loop holder was replaced by a piece of copper wire ( 5 $\mathrm{mm}$ in diameter) with one end flattened to $8 \mathrm{~mm}$ across. Five minuten pins were hotglued to the flattened end, with each pin being the same distance from the flattened edge. The stroke of the engraver was adjusted to approximately the midpoint. The minuten pins were held at an angle of approximately $45^{\circ}$ from the kernel adjacent to the embryo and pushed through the inoculum and the pericarp covering the scutellum at five different locations along both sides of the embryo to a depth of approximately $1 \mathrm{~mm}$. Following VPI, the glass dish, containing the seed and the wetted paper towels, was covered with clear plastic wrap and incubated at $30^{\circ} \mathrm{C}$ for $48 \mathrm{~h}$. Seed were then planted into 30by-50-cm soil-filled metal flats with 10 seeds per row. Each flat was lightly watered and held in a greenhouse under natural lighting with a temperature range of 17 to $27^{\circ} \mathrm{C}$.

Following establishment of the HPV isolates in 'Spirit' corn, each isolate was tested by ELISA against HPV and WSMV antiserum. All isolates tested negative for WSMV and positive for HPV. The minimum absorbance threshold value for WSMV was $1.8 \times$ the healthy control. This value was based on results from a preliminary experiment in which an extract from corn infected by both HPV and WSMV had an ELISA absorbance value for WSMV $1.9 \times$ the equivalent healthy control and was infective to wheat when leaf-rub inoculated (D. L. Seifers, unpublished data). For HPV, a positive absorbance threshold value was 0.054 . This value was based on results from a Western blot analysis that detected the $32-\mathrm{kDa}$ HPV protein in tissue that had an absorbance value as low as 0.054 in ELISA (19). In all subsequent VPI transfers of HPV isolates, all plants used for inoculum were tested prior to use by ELISA against HPV and WSMV antiserum to verify the purity of the HPV isolates.

Following the initial ELISA testing of the HPV-infected corn, plants testing negative in ELISA for WSMV and positive for HPV were then tested for the presence of viral proteins by minipurification and sodium dodecyl sulfate-polyacrylamide gel electrophoresis (SDS-PAGE), as described below.

Sources of antiserum. Antiserum against HPV was processed and used as previously reported (18). Antisera to WSMV (20), Agropyron mosaic virus (14), and Foxtail mosaic virus (16) were prepared as previously described. Antiserum to Brome mosaic virus (PV47AS) was obtained from the American Type Culture Collection (Manassas, VA). Antiserum to the American wheat striate mosaic virus was obtained from R. C. Sinha (Ottawa, Ontario, Canada) and used as previously described (15).

Minipurification, SDS-PAGE, estimation of relative molecular masses, and Western blotting of proteins. Extraction and minipurification of HPV protein followed the procedure of Lane (8). The method of Laemmli (7) was used for SDSPAGE and the detailed procedures were previously described (17). Mass standards (Sigma-Aldrich, St. Louis) used for SDSPAGE were: bovine serum albumin (66 $\mathrm{kDa})$, egg albumin (45 kDa), glyceraldehyde-3-phosphate-dehydrogenase (36 kDa), bovine carbonic anhydrase (29 $\mathrm{kDa})$, trypsinogen, bovine pancrease $(24 \mathrm{kDa})$, and b-lactalbumin, bovine milk (20 kDa). Relative molecular masses of HPV proteins were calculated from electrophoretic mobility measurements using a densitometer as described (20).

Electrophoretic analyses were conducted three times using extracts from different plants. Healthy plant tissue samples were treated and tested identically to test samples for all determinations.

Plant extractions and separations by SDS-PAGE and transfer of proteins onto nitrocellulose membranes were done as reported previously (17). Alkaline phosphatase antirabbit goat antibody (1:3,000 vol/vol dilution; Fisher Scientific, Chicago) was used for immunoblotting as described by Bollig and Edelstein (2). Mass standards used for Western blotting experiments were the prestained markers: $\beta$-galactosidase $(116 \mathrm{kDa})$, bovine serum albumin (80 kDa), ovalbumin (49 kDa), carbonic anhydrase $(32.5 \mathrm{kDa})$, soybean trypsin inhibitor $(27.5 \mathrm{kDa})$, and lysozyme (18.5 kDa) (BioRad, Hercules, CA).

Indirect ELISA. Detailed procedures were described earlier (18). Leaf tissue in all studies was ground at 1:30 (wt/vol dilution) in $0.05 \mathrm{M}$ carbonate buffer, $\mathrm{pH} 9.6$ (coating buffer) (3), and antiserum to HPV was used at a 1:50,000 dilution made from the 1:100 crossabsorbed stock in ELISA blocking buffer as described (18). The antirabbit antibody:alkaline phosphatase conjugate $(1: 3,000 \mathrm{vol} / \mathrm{vol})$ (Sigma-Aldrich) and WSMV antibodies (1:1,000 $\mathrm{vol} / \mathrm{vol}$ from a $1 \mathrm{mg} / \mathrm{ml}$ stock solution) were diluted using ELISA blocking buffer. All samples, antibody solutions, and sub- 
strate solutions were used at a $200-\mu \mathrm{l}$ volume. Substrate (p-nitrophenyl phosphate, $0.714 \mathrm{mg} / \mathrm{ml}$ ) in substrate buffer (3) was added to plates, which were incubated at room temperature, and the absorbance $\left(405_{\mathrm{nm}}\right)$ was measured after $30 \mathrm{~min}$ (Titertek Mulitskan Microelisa Plate Reader; Flow Laboratories, Inc., McLean, VA).

Infectivity assays. Tomahawk wheat and Spirit corn were inoculated manually with plant extracts $(1: 10 \mathrm{wt} / \mathrm{vol})$ to test for the presence of mechanically transmissible viruses as described (16). Inoculated plants were grown in a greenhouse under natural light at 19 to $30^{\circ} \mathrm{C}$.

WSMV sources and maintenance. WSMV isolates were obtained from the wheat plants infested by the WCM obtained from each location as stated above. This was done by initially infesting Tomahawk wheat with the appropriate WCM and allowing the colony to increase on these caged wheat plants. WSMV was then mechanically transferred by the finger-rub technique (17) from those wheat plants that tested positive in ELISA for WSMV to other Tomahawk wheat plants. The wheat plants were caged before and after mechanical inoculation to prevent WCM infestation. The original wheat plants from which WCM were obtained were also tested by ELISA against antiserum to Agropyron mosaic virus, American wheat striate mosaic virus, Brome mosaic virus, and HPV, as were the wheat plants that were infected by mechanical inoculation with extracts from the original wheat plants infested by WCM. The WSMVinfected plants were later tested for the presence of Foxtail mosaic virus. After establishment of the WSMV isolates in pure culture, they were tested by minipurification and SDS-PAGE to detect any viral capsid proteins not considered to be associated with WSMV. Throughout the study, source plants on which aviruliferous WCM were increased were tested by ELISA for the presence of HPV or WSMV to ensure that they were not contaminated with these viruses, and viruliferous colonies also were tested for HPV to ensure that each was free of this virus.

\section{RESULTS}

Serological relationship of HPV isolates. Once the HPV cultures were established, the individual isolates were tested by minipurification and SDS-PAGE for location and presence of the $32-\mathrm{kDa}$ protein associated with HPV-infected plants (Fig. 1A). In SDS-PAGE, all five HPV isolates displayed the identifying $32-\mathrm{kDa}$ protein. In Western blot analyses, the 32$\mathrm{kDa}$ HPV protein of the five HPV isolates reacted specifically to the antiserum probe made to this protein, with no reaction observed to any protein from healthy plant extracts (Fig. 1B, lane 7). In addition, no bands indicating the presence of WSMV or any other viruses were observed in any SDS-PAGE of separated proteins, nor were any of the isolates reactive to any antiserum other than HPV. In Western blots against WSMV antiserum, no reaction was observed to the HPV isolates, whereas the WSMV control was positive (data not shown). The average relative molecular masses (three analyses by SDS-PAGE) for the HPV protein were: Colorado, 32.9

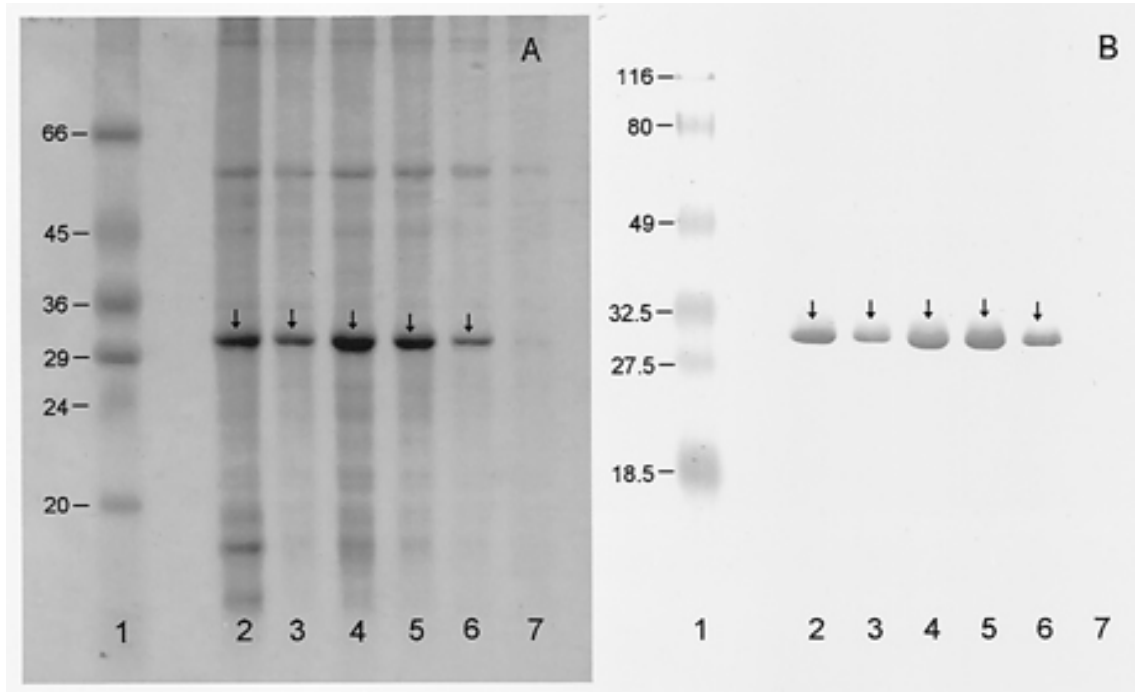

Fig. 1. A, Protein concentrated from 'Spirit' corn by minipurification, separated by sodium dodecyl sulfate-polyacrylamide gel electrophoresis; B, and probed with antibodies made to the 32-kDa protein of the High Plains virus (HPV). A, Lane 1, molecular mass standards (number to the left of the standards are in $\mathrm{kDa}$ ); lanes 2-6, corn infected by the Colorado, Idaho, Kansas, Texas, and Utah HPV isolates, respectively; and lane 7, healthy corn. Arrows in lanes 2-6 mark the location of the $32-\mathrm{kDa}$ protein associated with HPV. B, Western blot. Treatments in lanes 1-7 are as describe for A, except that lane 1 contains prestained mass markers. Arrows in lanes 2-6 mark the location of the protein of the different HPV isolates reacting with the antiserum probe made to the $32-\mathrm{kDa}$ HPV protein.
$\mathrm{kDa}$; Idaho $32.7 \mathrm{kDa}$; Kansas, $32.2 \mathrm{kDa}$; Texas, $32.1 \mathrm{kDa}$; and Utah, $32.3 \mathrm{kDa}$ (Fig. 1A). None of the HPV isolates was infective to wheat or corn by mechanical inoculation.

WCM transmission of HPV isolates. The NE WCM colony vectored all HPV isolates in all experiments in both the aviruliferous and viruliferous treatments (Table 1). For the NE WCM, the number of HPV-infected assay plants was not significantly different between the aviruliferous and viruliferous treatments for each HPV isolate; however, in the aviruliferous treatment, ID was different only from the KS and TX HPV isolates. NE WCM were a more efficient vector of all HPV isolates in the aviruliferous treatments compared with the other WCM. The MT WCM also vectored all HPV isolates in all experiments in the viruliferous treatment. However, in the aviruliferous treatment, only the KS HPV isolate was transmitted in all experiments (data not shown). The remaining HPV isolates were vectored in only one of the three experiments. The exact experiment (aviruliferous) in which vectoring occurred differed among isolates. For the MT WCM, treatment comparisons showed that the aviruliferous treatment had significantly fewer HPV-infected assay plants for all HPV isolates than its viruliferous treatment counterpart. The viruliferous MT WCM infected significantly more plants with the KS HPV isolate, followed by the CO HPV isolate, with significant differences existing among some but not all the remaining isolates, with the least numbers of plants infected with the UT HPV isolate. In contrast to the MT and NE WCM, the SD and TX WCM did not transmit any HPV isolate, and the KS WCM transmitted only the CO HPV isolate.

When 100 WCM were used, transmission of HPV isolates occurred that were not observed with the 10-WCM treatment. The TX WCM transmitted the ID (aviruliferous [1/10] and viruliferous [1/10] treatments), TX (viruliferous [1/10] treatment), and UT HPV (viruliferous [2/10] treatment) isolates; the SD WCM transmitted the ID HPV (aviruliferous [1/10] treatment) isolate; and the KS WCM vectored the KS (aviruliferous [1/11] treatment) isolate. However, analysis indicated no differences among the HPV isolates $\left(P r>\chi^{2}=0.24\right)$, but WCM sources, in both the aviruliferous and viruliferous treatments, showed significant interactions when analyzed across all HPV sources $\left(P>\chi^{2}=0.0001\right)$. In the aviruliferous treatment, the NE WCM had the largest number of infected plants and all NE WCM contrasts with other WCM sources were significant, whereas contrasts among all other WCM sources were not (Table 2). For the viruliferous treatments, the NE and MT WCM caused the most HPV infection. Contrasts between these 
two HPV sources were not significant, whereas all contrasts of the NE or MT WCM with the other WCM sources were significant (Table 2). Although the KS WCM did cause infection (1/51), it was not considered different from the SD WCM (0/54), where no infection occurred. Only the aviruliferous and viruliferous contrast for the MT WCM was significant $\left(\operatorname{Pr}>\chi^{2}\right.$ $=0.007$ ).

Only symptomatic barley plants tested positive for HPV in ELISA. All ELISA values for HPV-infected barley assay plants were above the 0.060 minimum threshold; the lowest ELISA value for all experiments was 0.097 , compared with the healthy barley control of 0.023 . No barley plants infested by aviruliferous WCM tested positive for WSMV, nor did any negative control plants. The numbers of WCM-infested barley assay plants infested over the three experiments ranged from 58 to 75. All WCM colonies by HPV isolate had one or more experiments in which the maximum of 25 plants were WCM infested.

All WCM in the viruliferous treatment were very efficient in transmitting WSMV to the barley assay plants. The range in percentages of WSMV-infected barley assay plants for the three experiments for each WCM colony were: Kansas, 74 to $100 \%$ (average 90\%); Montana, 91 to $100 \%$ (average 97\%); Nebraska, 82 to $100 \%$ (average 95\%); South Dakota, 90 to $100 \%$ (average 97\%); and Texas, 78 to $97 \%$ (average 90\%). These percentages are for all HPV tests of transmissions for a given WCM colony. The $74 \%$ for the KS WCM represents the three-experiment average from the KS HPV transmission tests; whereas, for the other experiments, $100 \%$ of the barley plants were WSMV infected when WSMV was in combination with any of the other HPV isolates and the KS WCM source. The $78 \%$ for the TX WCM represents the average WSMV infection rate when in combination with the $\mathrm{CO}$ HPV. Thus, for each WCM colony, the average WSMV-infection percentage represents the proportion of barley assay plants infected by WSMV for a given WCM-HPV combination.

\section{DISCUSSION}

Prior to this study, only Kansas and Nebraska HPV isolates had been characterized $(18,19)$. The present results provide the first confirmation that HPV isolates from a broad geographic range have the 32-kDa protein (Fig. 1A) and that this protein from each HPV isolate shows specific HPV antiserum binding in Western blot analysis (Fig. 1B) as shown for the Kansas and Nebraska isolates $(6,18,19)$. In addition to the five HPV isolates in this study, the $32-\mathrm{kDa}$ protein also has been observed for other Kansas HPV isolates in wheat, corn, and other grasses in the field $(18,19)$.

Our results demonstrated that the WCM colonies from the five states differed in their ability to transmit HPV. WCM have been demonstrated to vector WSMV (21), Wheat spot mosaic virus (22), the wheat spot mosaic pathogen $(12,13)$, and HPV (17). No vectoring studies using different sources of WCM have been conducted with the wheat spot pathogen or WSMV; therefore, no information is available showing the effect of variation in WCM origin on transmission of these pathogens. It had been demonstrated, however, that, although WCM obtained from various plant species could vector WSMV, WCM from hosts other than wheat transmitted the virus at much lower rates, which was attributed to poor adaptation of WCM from other plant species to wheat (4). In our studies, we obtained all colonies of WCM from wheat to avoid any complication associated with adaptation to this host. Thus, all our WCM colonies should have had similar feeding preferences on wheat. Although no information is available in the literature concerning effect of length of culture of WCM on ability to vector viruses, we obtained all WCM sources within 6 months of each other so that any effect related to length of culture on differences in transmission of HPV were not introduced in to the results.

We observed that the KS WCM vectored HPV poorly (Table 1). This observation is supported by our earlier field observations in Kansas, where we identified HPV infection in only $5 \%$ of the wheat plants analyzed compared with $56 \%$ for WSMV, indicating fewer HPV-harboring WCM (18). We also demonstrated the greater ability of the NE WCM to vector HPV, which is supported by field observations in Nebraska where $46 \%$ of wheat plants analyzed were infected by HPV compared with $65 \%$ for WSMV (11). Thus, one would expect increased numbers of HPVinfected plants from a more efficient vector population.

Our observation that the $\mathrm{KS}, \mathrm{SD}$, and TX WCM colonies could transmit certain

Table 2. Number of 'Westford' barley plants infected (NPI) by the High Plains virus (HPV) (across five HPV sources) when each plant was infested with 100 wheat curl mites (WCM) either aviruliferous or viruliferous for Wheat streak mosaic virus ${ }^{\mathrm{a}}$

\begin{tabular}{|c|c|c|c|c|c|c|}
\hline \multirow[b]{2}{*}{ WCM source ${ }^{b}$} & \multicolumn{3}{|c|}{ Aviruliferous } & \multicolumn{3}{|c|}{ Viruliferous } \\
\hline & NPI $^{c}$ & Contrast & $\operatorname{Pr}>\chi^{2}$ & NPI & Contrast & $\operatorname{Pr}>\chi^{2}$ \\
\hline KS & $3 / 47$ & KS-MT & 0.2431 & $1 / 51$ & KS-MT & $<0.0001$ \\
\hline MT & $5 / 33$ & KS-NE & $<0.0001$ & $16 / 31$ & KS-NE & $<0.0001$ \\
\hline NE & $24 / 37$ & KS-SD & 0.2395 & $26 / 38$ & KS-SD & 0.5383 \\
\hline SD & $1 / 64$ & KS-TX & 0.3607 & $0 / 54$ & KS-TX & 0.0069 \\
\hline \multirow[t]{6}{*}{ TX } & $1 / 52$ & MT-NE & $<0.0001$ & $4 / 51$ & MT-NE & 0.3377 \\
\hline & & MT-SD & 0.0411 & & MT-SD & $<0.0001$ \\
\hline & & MT-TX & 0.4513 & & MT-TX & $<0.0001$ \\
\hline & & NE-SD & $<0.0001$ & & NE-SD & $<0.0001$ \\
\hline & & NE-TX & $<0.0001$ & & NE-TX & $<0.0001$ \\
\hline & & SD-TX & 0.0250 & & SD-TX & 0.0026 \\
\hline
\end{tabular}

a There was a $95 \%$ confidence limit for $\chi^{2}$ comparisons.

${ }^{\mathrm{b}} \mathrm{KS}=$ Kansas, MT = Montana, NE = Nebraska, $\mathrm{SD}=$ South Dakota, and TX = Texas WCM.

${ }^{\mathrm{c}}$ Numerator represents the total number of HPV-infected plants and the denominator the total number of plants infested by WCM for all five HPV isolates for a given WCM source.

Table 1. Percentages of 'Westford' barley plants infected by the High Plains virus (HPV) following infestation with 10 aviruliferous (AV) or viruliferous (V) (Wheat streak mosaic virus) wheat curl mites (WCM) per plant ${ }^{\mathrm{a}}$

\begin{tabular}{|c|c|c|c|c|c|c|c|c|c|c|}
\hline \multirow[b]{3}{*}{ HPV isolate } & \multicolumn{10}{|c|}{ Sources of wheat curl mites } \\
\hline & \multicolumn{2}{|c|}{ Kansas } & \multicolumn{2}{|c|}{ Montana } & \multicolumn{2}{|c|}{ Nebraska } & \multicolumn{2}{|c|}{ South Dakota } & \multicolumn{2}{|c|}{ Texas } \\
\hline & $\mathbf{A V}$ & $\mathbf{V}$ & $\mathbf{A V}$ & $\mathbf{V}$ & $\mathbf{A V}$ & $\mathbf{V}$ & AV & $\mathbf{V}$ & AV & $\mathbf{V}$ \\
\hline Colorado & 3 & 10 & 3 & 61 & 37 & 56 & 0 & 0 & 0 & 0 \\
\hline Idaho & 0 & 0 & 1 & 54 & 9 & 38 & 0 & 0 & 0 & 0 \\
\hline Kansas & 0 & 0 & 5 & 94 & 74 & 45 & 0 & 0 & 0 & 0 \\
\hline Texas & 0 & 0 & 1 & 40 & 57 & 53 & 0 & 0 & 0 & 0 \\
\hline Utah & 0 & 0 & 1 & 20 & 41 & 34 & 0 & 0 & 0 & 0 \\
\hline
\end{tabular}

a Percentages of HPV infected plants following WCM infestation are from the results of three experiments. Data presented are actual values, not arcsine transformed percentages. The WCM previously had a 24-h acquisition feeding on 'Spirit' corn infected by different HPV isolates. Least significant difference $(0.05)=8,19$, and 37 in Kansas, Montana, and Nebraska, respectively. 
HPV isolates when $100 \mathrm{WCM}$ were used is important, indicating that these colonies evidently have fewer individuals in the population that acquired and transmitted HPV. It is very probable that all WCM sources we used could vector HPV at some level if very large numbers of WCM are used. This is probably what occurs under field conditions, where WCM can reach high numbers. Our Kansas field observations demonstrated that a low number of wheat plants were infected by HPV; that most infection occurred close to the source of the WCM, where the highest numbers of WCM occurred; and that, as distance from the WCM source increased, fewer WCM were present, as indicated by reduced WSMV infection and no HPV infection (18). Thus, under field conditions, it is probable that WCM sources from most locations can transmit HPV, if sufficient numbers of WCM are involved. For WCM sources such as NE and MT, high numbers of WCM would result in even higher numbers of infected plants in the field, translating to increased losses, which is in keeping with observation in Nebraska (11).

The MT WCM were shown to vector HPV more efficiently in the presence of WSMV in both the 10- and 100-WCM treatments (Tables 1 and 2). In the field, HPV infection usually occurs with that of WSMV $(5,11,18)$, although HPV infection can occur independently of WSMV (D. L. Seifers, unpublished data). It is possible that the source of the WSMV isolate can influence the level of HPV infection depending on the source of the WCM. The MT WCM had a MT WSMV source that was obtained from that WCM culture when received, as were the other WSMV sources for a particular WCM source. Interactions of this type were beyond the scope or our research, nor have they been investigated for the other pathogens (WSMV, Wheat spot mosaic virus, wheat spot mosaic pathogen) vectored by WCM.

Our results provide the first evidence that HPV sources from a wide geographic region are serologically related, have similar molecular masses as determined by SDS-PAGE, and could be maintained in pure culture by VPI. Also, we have demonstrated, by the interaction of WCM and the different HPV isolates, that the WCM colonies differed in ability to transmit these isolates. As discussed above, this phenomenon appears to be largely related to differences among the WCM colonies in their ability to transmit, rather than differences among HPV isolates to be transmitted. Thus, the epidemiology of HPV may be greatly influenced by variation in WCM populations. The influence of HPV isolate on virus spread may not be as important.

The present findings indicate a marked variation among WCM populations in their ability to transmit HPV related to population location; however, further study is needed to determine the frequency of occurrence of the variability among different WCM populations from within a location rather than variability of WCM populations from other locations. To assess this variability, additional WCM populations within each of the states from which the present colonies were obtained would need to be tested for ability to transmit HPV. This testing would access the withinstate or location variation in transmission ability among WCM populations.

Variation in HPV transmissibility affects the associated epidemiology of the virus, and this variation also could affect field evaluations for resistance to HPV. The transmissibility effect might be especially significant if the WCM population where the resistant selections were made was transmitting the virus poorly; thus, lines selected as having resistance may not perform as such when used in a location where a highly efficient HPV-transmitting WCM population occurred.

\section{LITERATURE CITED}

1. Ahn, K.-K., Kim, K. S., Gergerich, R. C., and Jensen, S. G. 1998. High plains disease of corn and wheat: Ultrastructural and serological aspects. J. Submicrosc. Cytol. Pathol. 30:563-571.

2. Bollig, D. M., and Edelstein, S. J. 1991. Immunoblotting. Pages 181-208 in: Protein Methods. Wiley-Liss, New York.

3. Clark, M. F., and Adams, A. N. 1977. Characteristics of the microplate method of enzymelinked immunosorbent assay for the detection of plant viruses. J. Gen. Virol. 34:475-483.

4. del Rosario, M. S. E., and Sill, W. H., Jr. 1965. Physiological strains of Aceria tulipae and their relationship to the transmission of wheat streak mosaic virus. Phytopathology 55:1168-1175.

5. Jensen, S. G., and Hall, J. S. 1995. Molecular characterization of a viral pathogen infecting maize and wheat in the high plains. (Abstr) Phytopathology 85:1211.

6. Jensen, S. G., Lane, L. C., and Seifers, D. L.
1996. A new disease of maize and wheat in the high plains. Plant Dis. 80:1387-1390.

7. Laemmli, U. K. 1970. Cleavage of structural proteins during the assembly of head of bacteriophage T4. Nature 227:680-685.

8. Lane, L. C. 1986. Propagation and purification of RNA plant viruses. Methods Enzymol. 118:687-696.

9. Little, T. M., and Hills, R. J. 1978. Agricultural Experimentation: Design and Analysis. John Wiley \& Sons, New York.

10. Louie, R., and Seifers, D. L. 1996. Transmission of the High Plains pathogen by vascular puncture inoculation. (Abstr.) Phytopathology 86:S1.

11. Mahmood, T., Hein, G. L., and Jensen, S. G. 1998. Mixed infection of hard red winter wheat with High Plains virus and wheat streak mosaic virus from wheat curl mites in $\mathrm{Ne}$ braska. Plant Dis. 82:311-315.

12. Nault, L. R., and Styer, W. E. 1970. Transmission of an eriophyid-borne wheat pathogen by Aceria tulipae. Phytopathology 60:16161618.

13. Nault, L. R., Styer, W. E., Gordon, D. T., Bradfute, O. E., Lafever, H. N., and Williams, L. E. 1970. An eriophyid-borne pathogen from Ohio and its relation to wheat spot mosaic virus. Plant Dis. Rep. 54:156-160.

14. Seifers, D. L. 1992. Partial characterization of a Colorado isolate of Agropyron mosaic virus. Plant Dis. 76:564-569.

15. Seifers, D. L., Harvey, T. L., and Bowden, R. L. 1995. Occurrence and symptom expression of American wheat striate mosaic virus in wheat in Kansas. Plant Dis. 79:853-858.

16. Seifers, D. L., Harvey, T. L., Haber, S., She, Y.-M., Chernushevich, I., Ens, W., and Standing, K. G. 1999. Natural infection of sorghum by foxtail mosaic virus in Kansas. Plant Dis. 83:905-912.

17. Seifers, D. L., Harvey, T. L., Kofoid, K. D., and Stegmeier, W. D. 1996. Natural infection of pearl millet and sorghum by wheat streak mosaic virus in Kansas. Plant Dis. 80:179185.

18. Seifers, D. L., Harvey, T. L., Martin, T. J., and Jensen, S. G. 1997. Identification of the wheat curl mite as the vector of the High Plains virus of corn and wheat. Plant Dis. 81:11611166.

19. Seifers, D. L., Harvey, T. L., Martin, T. J., and Jensen, S. G. 1998. A partial host range of the High Plains virus of corn and wheat. Plant Dis. $82: 875-879$.

20. Seifers, D. L., Martin, T. J., Harvey, T. L., and Gill, B. S. 1995. Temperature sensitivity and efficacy of wheat streak mosaic virus resistance derived from Agropyron intermedium. Plant Dis. 79:1104-1106.

21. Slykhuis, J. T. 1955. Aceria tulipae Keifer (Acaria: Eriophyidae) in relation to the spread of wheat streak mosaic. Phytopathology 45:116-128.

22. Slykhuis, J. T. 1956. Wheat spot mosaic, caused by a mite-transmitted virus associated with wheat streak mosaic. Phytopathology 46:682-687. 